\title{
25 Research Square

\section{A More Complete Story of the Genetic Bases of Resistance to the Rice Hoja Blanca Virus}

\author{
Alexander Silva \\ Alliance Bioversity-CIAT \\ María Elker Montoya \\ FLAR - Fondo Latinoamericano para Arroz de Riego \\ Constanza Quintero \\ Alliance Bioversity-CIAT \\ Juan Cuasquer \\ Alliance Bioversity-CIAT \\ Joe Tohme \\ Alliance Bioversity-CIAT \\ Eduardo Graterol \\ FLAR - Fondo Latinoamericano para Arroz de Riego \\ Maribel Cruz \\ FLAR - Fondo Latinoamericano para Arroz de Riego \\ Mathias Lorieux ( $\square$ mathias.lorieux@ird.fr) \\ DIADE, University of Montpellier, Cirad, IRD, Montpellier
}

\section{Research Article}

Keywords: Rice hoja blanca virus (RHBV), Disease severity, Disease incidence, Quantitative trait locus $(\mathrm{QTL})$, candidate gene

Posted Date: January 7th, 2022

DOI: https://doi.org/10.21203/rs.3.rs-1225485/v1

License: (c) (1) This work is licensed under a Creative Commons Attribution 4.0 International License.

Read Full License 


\section{Abstract}

Rice hoja blanca is one of the most serious diseases in rice growing areas in tropical Americas. Its causal agent is the Rice hoja blanca virus (RHBV), transmitted by the planthopper Tagosodes orizicolus Müir. Genetic resistance is the most effective and environment-friendly way of controlling the disease. So far, only one major quantitative trait locus (QTL) of Oryza sativa ssp. japonica origin, qHBV4.1, that alters incidence of the virus symptoms in two Colombian cultivars has been reported. This resistance has already started to be broken, stressing the urgent need for diversifying the resistance sources. In the present study we performed a search for new QTLs of $O$. sativa indica origin associated with RHBV resistance. We used four $\mathrm{F}_{2: 3}$ segregating populations derived from indica resistant varieties crossed with a highly susceptible japonica pivot parent. Beside the standard method for measuring disease incidence, we developed a new method based on computer-assisted image processing to determine the affected leaf area (ALA) as a measure of symptoms severity. Based on the disease severity and incidence scores in the $F_{3}$ families under greenhouse conditions, and SNP genotyping of the $F_{2}$ individuals, we identified four new indica QTLs for RHBV resistance on rice chromosomes 4, 6 and 11, namely qHBV4.2WAS208, $q H B V 6.1^{\text {PTB25 }}, q H B V 11.1$ and $q H B V 11.2$. We also confirmed the wide-range action of $q H B V 4.1$. Among the five QTLs, $q H B V 4.1$ and $q H B V 11.1$ had the largest effects on incidence and severity, respectively. These results provide a more complete understanding of the genetic bases of RHBV resistance in the cultivated rice gene pool, and can be used to develop marker-aided breeding strategies to improve RHBV resistance. The power of joint- and meta- analyses allowed precise mapping and candidate genes identification, providing the basis for positional cloning of the two major QTLs qHBV4.1 and qHBV11.1.

\section{Introduction}

The rice hoja blanca $(\mathrm{RHB})$ disease is one of the most important constraints to rice productivity in the tropical zone of Americas, causing yield losses in many countries, including Colombia, Costa Rica, Ecuador, Guyana, Panama, Peru, Dominican Republic, Nicaragua and Venezuela (Morales and Jennings 2010). Its causal agent is the Rice hoja blanca virus (RHBV), a Tenuivirus transmitted by the planthopper Tagosodes orizicolus M. (Hemiptera:Delphacidae). Genetic resistance to both the virus and its vector insect is key for a successful, environment- and consumers health-friendly, integrated crop management. No real immunity has been found in the cultivated rice germplasm, and even in resistant materials, the plantlets ( $<10$ days old) can show susceptibility to the virus. Nonetheless, a handful of varieties including the two Colombian cultivars, Fedearroz 50 and Fedearroz 2000 - with good resistance level have been bred in the past and have been important to stabilize rice production. Fedearroz 2000 is still the most resistant commercial variety, however, the incidence of the disease has increased under field and controlled conditions. Fedearroz 50 has turned virus-susceptible in the past years in the field, probably due to virus mutations that allowed it to overcome the resistance. Thus, there is an urgent need for diversifying the sources of genetic resistance in order to breed new varieties with more durable resistance. Genetic resistance to RHB disease can be decomposed into resistance to the virusitself, and resistance to its insect vector. In the present study, we focus on resistance to the virus. 
In a previous study, we reported a major QTL on the short arm of chromosome four for resistance to RHBV, shared by Fedearroz 50 and Fedearroz 2000, abbreviated as FD 50 and FD 2000 in this paper (Romero et al. 2014). This QTL, called here qHBV4.1, controlled RHBV incidence, measured as the percentage of plants that show symptoms of the viral infection, no matter the level of the symptoms. Incidence is of course an important parameter of the epidemics of a disease. Yet, its severity is certainly as much as important: if severity is low, a high incidence might have no significant impact on plant viability, panicle development, or grain yield. Additional to RHBV incidence, we thus designed - and report in this study - new experiments to decipher the genetic control of RHBV resistance seen as symptoms severity, measured by computer-aided image processing of the affected leaf area (ALA).

Moreover, a local ancestry analysis showed that, although FD 50 and FD 2000 are mostly of Indica genetic background, qHBV4.1 in those two cultivars was found to be of Japonica origin, and was surrounded by several hundred kilobase pairs of Japonica DNA. We found desirable to search for Indica resistance QTLs in order to ensure better compatibility with tropical irrigated materials in breeding programs, and also to increase the diversity of the available sources of genetic resistance. Based on the encouraging screening work by the FLAR (Fondo Latinoamericano para Arroz de Riego) team (CruzGallego et al. 2018), we thus designed a new QTL analysis based on four crosses involving new resistance sources.

\section{Materials And Methods Plant materials}

Four 0 . sativa ssp. indica accessions were selected amongst the most resistant materials identified in (Cruz-Gallego et al. 2018): WAS 208-B-B-5-1-1-3 (IRGC 121855) thereafter abbreviated as WAS 208), Badkalamkati (IRGC 45011) (abb. Badka), PTB 25 (IRGC 6386) and Fedearroz 2000 (IRGC 124388) (abb. FD 2000). The main selection criteria were (1) selected sources should show a consistent, high resistance to RHBV and (2) they should cover the genetic diversity spectrum of the indica cluster. Then, the four resistance sources were crossed with the highly susceptible japonica line Bluebonnet 50 (IRGC 121874) (abb. BBT 50), using BBT 50 as the male parent. Candidate $F_{1}$ hybrids were checked for self-pollination of the mother plant with 48 SNP (single nucleotide polymorphism) markers distributed along the rice genome. $F_{2}\left(S_{1}\right)$ populations were derived from self-pollination of the verified $F_{1}$ hybrids. Each $F_{2}$ plant was self-pollinated to produce $F_{3}\left(S_{2}\right)$ families. All panicles involved in crosses or self-pollination were bagged to avoid out-crossing.

\section{Population sizes}

The following population sizes were used for both genotyping in $F_{2}$ plants and trait scoring in $\mathrm{F}_{3}$ families: WAS 208 'BBT 50: $104 \mathrm{~F}_{2}, 1,040 \mathrm{~F}_{3}$ (ALA), 6,240 $\mathrm{F}_{3}$ (incidence); Badka 'BBT 50: $105 \mathrm{~F}_{2}, 1,050 \mathrm{~F}_{3}$ (ALA), 6,300 F (incidence); PTB 25 ' BBT 50: $108 \mathrm{~F}_{2}, 1,080 \mathrm{~F}_{3}, 6,480$ (incidence); FD 2000 ` BBT 50: $105 \mathrm{~F}_{2}$, 
$1,050 \mathrm{~F}_{3}$ (ALA), 6,300 $\mathrm{F}_{3}$ (incidence). Populations sizes for ALA scoring are significantly lower than for incidence, however, as ALA is assessed using tube-based phenotyping (non-choice feeding test), precision is higher than for incidence measured in trays (see hereby).

\section{Evaluation of RHBV resistance}

To evaluate the level of resistance - or susceptibility - of the $F_{3}$ plants, we looked at two complementary aspects of the disease: the incidence and the severity of the symptoms. Incidence is simply defined by the proportion of diseased plants in a population, while severity is the area or volume of plant tissue that is visibly diseased (Campbell and Neher 1994). The $F_{3}$ families, parents and check lines were evaluated under greenhouse conditions, at the CIAT (Centro Internacional de Agricultura Tropical) headquarters in Palmira, Colombia.

\section{Virulent insect colonies}

T. orizicolus virulent insects were obtained from colonies maintained at CIAT. The RHBV harboring colony contained insects that were fed on RHBV-infected plants and allowed to reproduce on BBT 50. To determine the percentage of virulent insects in this colony, 200 individual nymphs were tested for virulence on separate, caged, RHB-susceptible 8-day-old seedlings.

\section{Incidence}

Here we consider incidence as the percentage of plants showing any level of RHBV symptoms. We consider the absence of symptoms as a sign of absence of infection, not as extreme tolerance. $F_{3}$ materials and controls were planted in plastic trays containing 17 furrows of 20 plants each. Each tray contained a furrow of each parent - BBT 50 also served as a susceptible control - and the controls FD 2000 (resistant) and Colombia 1 (intermediate). The trays were placed in a mesh cage 18 days after sowing, and infested by mass release of $T$. orizicolus with virulence between $50 \%$ and $65 \%$, with an average of four nymphs per plant. The nymphs were allowed to feed for three days on the plants, after which they were eliminated with water rinsing. A randomized complete block design was used with three replicates (20 plants from each $\mathrm{F}_{3}$ family per replicate), where each block represented a cage. Incidence assessment was made 35 days after infestation (DAI) by counting the plants showing disease symptoms, per row.

\section{Severity}

In order to test the severity of RHBV, a novel methodology based on the affected leaf area (ALA) by the virus was developed using an image processing approach. Briefly, images of infected plants were taken using a reference scale (a ruler) and a contrasting background under homogeneous light exposure. Raw images of plants with symptoms (Figure 1A) are processed using the Image J software in two steps: in the first step, brightness is decreased to eliminate the areas affected by the disease (Figure 1B). Then, the 
image is binarized, i.e., converted to black and white (Figure 1C). The number of black pixels is thus representing the healthy area of the leaf, according to the previously calibrated reference scale. In the second step, a binarization process allows to calculate the total area (Figure 1D). The affected area is then calculated as the difference between total and healthy areas.

\section{Statistical treatment}

Since ALA was measured as the ratio of affected/total leaf area for each family in each block, a weighted ALA was calculatedwith a generalized linear mixed model (MLGM) using the gamma distribution. The incidence variable was analyzed with a MLGM using the binomial distribution. The MLGM procedure is used for variables that are not necessarily normally distributed. For each variable, an analysis of variance was performed to test for differences between families and to evaluate the effect of the blocks. Subsequently, adjusted means were calculated for each family and a mean comparison test was performed to identify those families that were more resistant or equal to the resistant parent. The descriptive analysis was performed in the R program and the other analyses were performed in the SAS ${ }^{\circledR}$ statistical program.

\section{SNP marker development}

Whole-genome sequences of parental lines, available from previous studies (Li et al. 2014; Duitama et al. 2015; Cruz-Gallego et al. 2018) and the IRGSP 1.0 Nipponbare reference genome were compared in silico using the Next Generation Sequencing Eclipse Plugin, NGSEP (Duitama et al. 2014). Variant detection and annotation were performed with NGSEP and SNP positions were determined relative to the reference genome. Informative biallelic SNPs were filtered based on the following characteristics of their flanking sequence: minimum 30 bp between the target SNP and other variant and GC content between 20 and $65 \%$. The flanking sequence of $100 \mathrm{bp}$ upstream and downstream the target SNP was retrieved and submitted to D3 assay design web-based tool (https://d3.fluidigm.com) to develop Fluidigm ${ }^{\circledR}$ SNPtype assays. SNPs were chosen based on their design quality score and their genomic position.

\section{DNA extraction}

Leaf tissue was collected from 15-days-old F2 plants. Samples were frozen in liquid nitrogen and stored at $-80^{\circ} \mathrm{C}$ until processed. Plant DNA was isolated in 96-racked tubes using a modified version of a method previously described (Risterucci et al. 2000) as follows: $480 \mu$ l extraction buffer was added to $150 \mathrm{mg}$ ground frozen leaf tissue. The buffer was $100 \mathrm{mM}$ Tris ( $\mathrm{pH}=8.0), 2 \mathrm{M} \mathrm{NaCl}, 20 \mathrm{mM}$ EDTA ( $\mathrm{pH}=$ 8.0), MATAB $2 \%$, sodium bisulfite $0.5 \%$, and PEG $80001 \%$. This mixture was homogenized and incubated in a water bath at $74^{\circ} \mathrm{C}$ for $30 \mathrm{~min}$. Subsequently, $480 \mu \mathrm{l}$ chloroform:isoamyl-alcohol (24:1) was added and the mixture was centrifuged at $3000 \mathrm{rpm}$. Supernatants were precipitated with $270 \mu \mathrm{l}$ isopropanol at $-20^{\circ} \mathrm{C}$ for one hour and centrifuged at 3000rpm. The pellets were washed with $200 \mu \mathrm{l} 80 \%$ ethanol and 
allowed to dry at $40^{\circ} \mathrm{C}$ by inverting the tubes for one hour. DNA was resuspended in Tris-EDTA [10 mM Tris- $\mathrm{HCl}, \mathrm{pH} 8$ and $1 \mathrm{mM}$ EDTA, pH8) containing $40 \mu \mathrm{g} / \mathrm{ml}$ of RNAse A and spectrophotometric quantification was done using a multimode plate reader Synergy H1 (Biotek). DNAs were normalized at $60 \mathrm{ng} / \mu \mathrm{l}$ for subsequent processing.

\section{Genotype scoring}

$\mathrm{F}_{2}$ individuals and parents were scored for polymorphic SNPs in each population using the Fluidigm nanofluidic genotyping platform, according to the manufacturer's protocols. Briefly, pre-amplification of targets regions was done in a $5 \mu \mathrm{l}$ multiplex-PCR reaction, used as template for allele specific-PCR that was conducted in 48 ' 48 integrated fluidic circuit (IFCs) of the Fluidigm ${ }^{\circledR}$ genotyping platform. Fluorescent images of the IFCs were acquired in an EP1 reader and analyzed with the Fluidigm Genotyping Analysis Software.

\section{Linkage maps construction}

Genetic maps were calculated with MapDisto 2.0 (Lorieux 2012; Heffelfinger et al. 2017) (http://mapdisto.free.fr). Goodness-of-fit to Mendelian segregation (1:2:1) was tested for each marker by computing the chi-squared ( $c 2$ ) statistic with the 'Segregation $c 2 s$ ' function. As the SNP markers were defined from WGS, we kept their order on the physical map or rice. For each cross separately, we checked the data for singletons (e.g., the "B" in "AAAAAAABAAAAAA" is a singleton) with the 'Replace errors by flanking genotypes' function, with a maximum probability of a singleton to occur of 0.001. A few missing data were inferred using the 'Replace missing data by flanking genotypes' function, with the same threshold. Recombination fractions were converted to centimorgans (cM) with the Kosambi mapping function (Kosambi 1944).

\section{QTL mapping}

Data files were prepared using the 'Export map and data' function of MapDisto 2.0. Analyses of distribution of the phenotypic traits as well as QTL detection were performed using the Qgene 4.0 program (Joehanes and Nelson 2008) (http://www.qgene.org). For QTL detection, the LOD score statistic was calculated with the following different methods were compared: single-marker regression (SMR), simple interval mapping (SIM) and composite interval mapping (CIM). The forward cofactor selection option was used in CIM. Empirical thresholds to declare the presence of a QTL were obtained using the resampling by permutation method, performing 10,000 (SMR) or 1,000 (CIM) iterations for each traitchromosome combination. In order to correct for possible erroneous phenotypic data corresponding to escape, mis-scoring, or incomplete penetrance, all positive QTLs were additionally confirmed by analysis of outliers in the trait distribution using the 'Plot trait vs. genotype' module of MapDisto. This module 
allows to calculate corrected single-marker regression F-test values after detecting and removing outlier data in each marker genotypic sub-class.

In the case of a secondary LOD score peak linked to a major peak of a QTL, in order to determine if the secondary peak corresponded to a true QTL or to an artifact - or "fake QTL" - a detailed analysis of the distribution of recombination fractions along the chromosome was performed, flowing the method of (Lorieux 2018). The analysis looked for restriction of recombination fractions that could induce artificial linkage disequilibrium between the major and the secondary LOD score peaks. If artificial linkage disequilibrium was detected, then the secondary peak was declared an artifact. Interaction or epistasis was tested using the R/qtl 'Scantwo' function (Prins et al. 2010).

When a QTL is found in more than one cross, joint or meta-analysis can increase the precision of the QTL location. As different markers segregated in the four populations, we created a genotype matrix from the union of the four individual data sets. Markers with no data in some of the populations were imputed using the R/qtl 'Argmax' function. Joint- and meta-QTL analyses were then ran using MapDisto 2.0.

To identify candidate genes in the fine-mapped regions, the MSU Rice genome annotation database and the Overview of Functionally Characterized Genes in Rice Online database (OGRO) (Yamamoto et al. 2012) were used. A 1-LOD support interval was used to define the search region for each QTL.

\section{Results}

\section{Genetic maps}

Table 1 summarizes the main statistics of the individual genetic maps obtained for each cross. Overall, we obtained genetic map sizes coherent with their expected size according to ten high-quality maps based on flexible and scalable genotyping by sequencing (fsGBS) (Heffelfinger et al. 2014; Fragoso et al. 2017), indicating the good level of purity of the $F_{2}$ populations and the high quality of the SNP data.

Segregation distortion (SD): SD was observed on chromosome 3 (11.1-21.0 Mbp) in the crosses involving WAS 208, Badka and FD 2000. This region is commonly affected by SD in indica' japonica crosses (Wang et al. 2009; Fragoso et al. 2017). The homozygotes for the donor allele (AA genotype) were favored over both the homozygotes for the susceptible parent allele (BB genotype) and the heterozygotes (AB). In the cross WAS $208^{\prime}$ BBT 50 cross, a pattern of SD was also observed on chromosome 8 (3.53-16.44 Mbp), where the AB genotypes were favored over the AA. In the cross PTB 25 ' BBT 50, segregation distortion was observed on chromosomes 2 (20.1 Mbp, 47AA:50AB:11BB), 6 (2.9-7.9 Mbp, 34AA:64AB:10BB) and 9 (10.8-12.2 Mbp, 42AA:54AB:12BB).

\section{RHBV incidence and severity variation}


In the cross WAS 208 'BBT 50 , the parental lines showed $24 \%$ and $98 \%$ of incidence and $25.8 \%$ and $69.5 \%$ of RHBV severity in WAS 208 and BBT 50, respectively. The $F_{3}$ families (each representing one $F_{2}$ parental plant) exhibited a continuous variation of incidence ranged between $21.4 \%$ and $100 \%$, as well as a variation of severity ranged between $9 \%$ and $68 \%$ (Figure 2 ). The high incidence score for the susceptible parent BBT 50 - almost $100 \%$ - and the maximum values in the $F_{3}$ families indicate a perfect infection efficiency. The similarity between the severity score for BBT 50 and the maximum scores in $\mathrm{F}_{3}$ families indicates that the experimental design, and in particular the population size, were adequate to capture the range of variation between the parental values. Interestingly, some $F_{3}$ families exhibited a significant lower severity than the resistant parent WAS 208.

In the cross Badka 'BBT 50, the resistant and susceptible parents exhibited $32.8 \%$ and $98.9 \%$ of RHBV incidence, respectively. In the same order, these parents displayed $35.3 \%$ and $82 \%$ of severity. The incidence in the $F_{3}$ families ranged between $13 \%$ to $98 \%$, and the severity varied between $11 \%$ and $80 \%$ (Figure 2). A positive correlation between incidence and severity of the disease was detected $(r=0.56$, $p<0.0001$ ), suggesting a common partial genetic control for both assessments of RHBV disease. Some $F_{3}$ families exhibited lower incidence and severity than the resistant parent Badka.

In the cross PTB $25 \times$ BBT 50, the incidence of the resistant and susceptible parents was $3.4 \%$ and $98.2 \%$, respectively, and ranged between $5 \%$ to $96 \%$ in the $F_{3}$ families. Furthermore, PTB 25 and BBT 50 showed $11.8 \%$ and $68 \%$ of severity, respectively. The same trait varied between $7 \%$ and $69 \%$ in the $F_{3}$ families.

In the cross FD 2000 ' BBT 50, the resistant and susceptible parents showed $20.8 \%$ and $75.4 \%$ of RHBV incidence, and $3.4 \%$ and $50.1 \%$ of severity, respectively. In the $F_{3}$ families; incidence ranged between $10 \%$ and $90 \%$, and severity between $0 \%$ and $59 \%$. The incidence and severity for the susceptible parent BBT 50 were notably lower than in the crosses before mentioned, indicating a low infection efficiency that can affect the power of QTL detection and the QTL effects estimation. In contrast, the incidence of FD 2000 was higher than in previous works (Romero et al. 2014; Cruz-Gallego et al. 2018).

Incidence and severity showed correlation between 0.42 and 0.66 (Table 2), indicating either a common genetic control of the two traits, or that they are interdependent.

\section{The major QTL $q H B V 4.1$ for RHBV incidence is present in most donors}

A major QTL, qHBV4.1, on chromosome 4 for RHBV incidence was identified by SMR, SIM and CIM in the crosses Badka 'BBT 50 (LOD=20.97, $\left.\mathrm{R}^{2}=0.63\right)$, PTB $25^{\prime}$ BBT $50\left(\mathrm{LOD}=21.26, \mathrm{R}^{2}=0.60\right)$ and FD 2000 'BBT 50 ( $L O D=9.11, R^{2}=0.34$ ) (Table 3). It was not detected in the cross WAS 208 'BBT 50, although a fake QTL analysis (Lorieux 2018) showed that it could be present in WAS 208, but with a much smaller effect (data not shown). The QTL support intervals are overlapping in the three populations, suggesting that the same QTL is shared by the three resistance donors. Joint analysis gave 
a $\mathrm{LOD}=47.00$ and $\mathrm{R}^{2}=0.42$ at the position $\sim 3.56 \mathrm{Mbp}$. The $q H B V 4.1$ position also corresponds to a previously identified locus characterized as the major contributor to RHBV resistance in FD 2000 and FD 50 (Romero et al., 2014), confirming the wide range of action of this QTL. It explained $34-63 \%$ of the trait variance, indicating that $q H B V 4.1$ is a major regulating factor of incidence of RHBV infection. The estimation of QTL effects for qHBV4.1 showed that this QTL is mostly of the additive type. The same genomic region was also associated with RHBV severity in the same crosses, however with lower LOD scores and $R^{2}$ values $\left(\mathrm{LOD}=6.69-8.50, \mathrm{R}^{2}=25-31 \%\right)$.

\section{A new major QTL for RHBV incidence, $q H B V 4.2$, identified in WAS 208}

The control of RHBV incidence in WAS 208 was mainly explained by a different QTL on chromosome 4, designated as $q H B V 4.2^{\text {WAS208 }}\left(\mathrm{LOD}=15.49, \mathrm{R}^{2}=0.52\right)$ by SMR, SIM and CIM. This QTL was not found in the other crosses (Table 3). This newly discovered QTL was located between 21.29 and $21.81 \mathrm{Mbp}$ and explained $52 \%$ of the incidence variance. $q H B V 4.2$ is therefore another major QTL for RHBV incidence that seems less frequent than $q H B V 4.1$ in the rice germplasm.

\section{Two new QTLs for RHBV incidence identified in WAS 208 and PTB 25}

Two additional QTLs, although of lesser effect, were detected for RHBV incidence (Table 4):

- qHBV6. $1^{\text {PTB25 }}$ on chromosome 6 (0.18-1.76 Mbp, $\left.\operatorname{LOD}_{\mathrm{SIM}}=3.64, \mathrm{LOD}_{\mathrm{CIM}}=9.71, \mathrm{R}^{2}=25 \%\right)$, mostly of the additive type effect and detected in the PTB 25 ' BBT 50 cross only.

- qHBV11.2 on chromosome 11 in the crosses involving WAS 208 (7.43-11.9 Mbp, $\operatorname{LOD}_{\mathrm{CIM}}=5.02$, $\mathrm{R}^{2}=21 \%$ ) and PTB 25 (7.43-16.6 Mbp, $\left.\mathrm{LOD}_{\mathrm{CIM}}=5.9, \mathrm{R}^{2}=24.2 \%\right)$. However, the SMR or SIM methods produced LOD scores under the retained threshold (Tables 3 and 5).

\section{A new QTL, qHBV11.1, controls RHBV severity}

One of the most interesting results of this work is the discovery of a new QTL associated with RHBV symptoms severity (measured as ALA). It was detected on chromosome 11 in the crosses WAS 208 ' BBT 50 (18.0-18.8 Mbp, LOD=5.32, $\mathrm{R}^{2}=0.21$ ), Badka 'BBT 50 (17.8-18.5 Mbp, LOD=4.68, $\mathrm{R}^{2}=0.19$ ) and FD 2000 'BBT 50 (17.8-18.5 Mbp, LOD=8.98, $\left.\mathrm{R}^{2}=0.33\right)$. This $\mathrm{QTL}$ was designated as $q H B V 11.1$ and explained $17-33 \%$ (SIM) or 19-37\% (CIM) of the trait variation, depending on the cross (Tables 3 and 4 ). The QTL effects in the populations involving WAS 208 and Badka indicate an additive behavior of qHBV11.1, while in FD 2000 ' BBT 50 it seems to be more dominant (Table 3). Due to the correlation 
between incidence and severity, qHBV11.1 was also significant for RHBV incidence in the cross FD 2000 ' $B B T 50$ although with lower statistics $\left(L O D=7.43, R^{2}=0.29\right)$, confirming that this $Q T L$ is controlling primarily the RHBV severity.

\section{The $q H B V 4.1$ and $q H B V 11.1$ QTLs show strong interaction}

Testing interaction between QTL regions with the R/qtl "scantwo" function produced a strong signal between the two QTLs qHBV4.1 and qHBV11.1 (LOD>15)(Figure S1), revealing either an epistasis relationship between the two regions, or a simple interdependency between the two traits. This is coherent with the positive correlation observed between severity and incidence.

\section{Joint- and meta-analyses provide good candidates for QTL cloning}

The joint and meta-analyses approaches allow pooling populations, providing more resolution for QTL mapping. This allowed us identifying candidate genes that could underlie two of the QTLs we discovered.

\section{The qHBV4.1 region contains the AGO-4 Argonaute gene}

In the qHBV4.1 region, 33 genes encoding proteins with unknown function, five hypothetical genes, four genes encoding different types of kinases, two genes of the MEG (maternally expressed gene) family involved in the translocation of nutrients to the seed, and one Argonaute gene were identified. The most interesting gene within the $q H B V 4.1$ region is probably the Argonaute AGO-4 (MSU: LOC_Os04g06770, Chr4:3,562,793-3,555,220bp). AGO proteins are effector proteins of RNA silencing pathways, which regulate gene expression in a sequence-specific manner (Duan et al. 2015). RNA silencing is also the main antiviral defense mechanism possessed by plants. It can be post-transcriptional (PTGS) or transcriptional (TGS) (Carbonell and Carrington 2015).

\section{The qHBV11.1 region contains a gene for durable resistance to Rice stripe virus}

The genomic region of $q H B V 11.1$ contains many nucleotide binding site-leucine-rich repeat (NBS-LRR) genes, which are broadly known to confer resistance to multiple diseases (McHale et al. 2006). Other types of genes are also found in the interval, and remarkably the STV11 gene (MSU:LOC_Os11g30910, Chr11:17,984,964-17,986,719b; RAP-DB: Os11g0505300), which confers durable resistance to Rice stripe virus (RSV), one of the most devastative viral diseases of rice in Asia (Wang et al. 2014). Interestingly, this virus belongs to the same genus as RHBV and it is also transmitted by planthoppers (Laodelphax striatellus Fallen). It should be also noted that, very close to the qHBV11.1 support interval, there are 
several paralog histidine kinase/Hsp90-like ATPase genes (MSU:LOC_Os11g31480, MSU:LOC_Os11g31500) that also confer resistance to RSV (Hayano-Saito and Hayashi, 2020).

\section{Discussion}

Successful genotype-phenotype association studies require precise methodologies to assess phenotypic variables. The latest technological advances in image acquisition have allowed the development of computer tools for picture processing and analysis that provide accurate data. Image processing for quantifying damage caused by plant diseases is particularly useful as it advantageously replaces traditional scoring scales, which are too dependent on the observer. The RHB disease has been commonly evaluated using the percentage of diseased plants at a given time - that is, the incidence. However, the main drawback of this approach is that it classifies all the plants with symptoms in the same class, without considering the level of damage - the severity. Understanding the genetic mechanisms of resistance to the hoja blanca disease therefore requires proper assessment of not only its incidence but also its severity. In this sense, we proposed for the first time the use of digital images to evaluate the severity of damage caused by RHBV by estimating the affected leaf area. We showed that severity varies continuously among $\mathrm{F}_{3}$ families, a characteristic behavior of quantitative features.

Severity and incidence evaluation allowed us to identify different QTLs, allowing us to better explain the complexity of the genetics of resistance to RHBV. Keeping in mind that the parents of the four populations were among the most resistant of a larger panel (Cruz et al. 2018), and although significant differences between incidence and severity were found among the parents of the four populations, complete resistance was not observed, confirming a previous observation by (Morales and Jennings 2010) about the lack of immunity to RHBV in the $O$. sativa genepool.

\section{RHBV resistance is regulated by multiple QTLs}

The QTLs found in this study show that resistance to RHBV, assessed both by affected leaf area and incidence, is controlled by multiple genes. The co-location of LOD score peaks for incidence in the same region of chromosome 4 in three different crosses suggests that it is likely the same QTL, namely $q H B V 4.1$. Although $q H B V 4.1$ was associated to both phenotypic variables, its association was greater with incidence where it explained up to $63.6 \%$ of the phenotypic variance. These results suggest that the main action of $q H B V 4.1$ could take place in the first phase of the interaction of the virus with the plant, preventing the virus to enter and propagate in the plant, which is reflected in a smaller number of plants with symptoms. In addition, the little variation in nucleotides - less than $1 \%$ - in the region of $q H B V 4.1$, between Badka and PTB 25 indicates a probable common local ancestry (Figure S2). The differences in the LOD score (5.83 vs. 8.26) and in $\mathrm{R}^{2}$ values (21.4\% vs. $\left.36.6 \%\right)$ for ALA, in these two populations, could be explained by the difference in the percentage of virulence of the vector colonies, which were $~ 69 \%$ and $\sim 46 \%$ for Badka 'BBT 50 and PTB 25' BBT 50, respectively. Also, the phenotypic evaluation trials were performed at different times of the year for the different populations. This involves the use of different 
vector colonies, and implies variations in microenvironmental factors such as day and night temperature, radiation or humidity that might affect the behavior of the insect and its ability to transmit the virus.

A major QTL had been previously identified in the region of $q H B V 4.1$ in the varieties FD 2000 and Fedearroz 50 by incidence assessment (Romero et al. 2014), which suggests a predominant, common mechanism of resistance to RHBV in the different clades of Oryza sativa. The genetic variation between the parents observed in this region shows that they carry different alleles, of Japonica and Indica origins. This has implications for crop improvement, allowing breeders to broaden the genetic base of resistance in elite germplasm. A QTL for resistance to Rice stripe virus (RSV) has been identified between 4.4 and $6.9 \mathrm{Mpb}$ in the N22 Aus variety (Wang et al. 2013). The qHBV4.1 QTL region might thus contain at least two tenuivirus resistance genes. As mentioned above, in the region of $q H B V 4.1$ there is a putative gene that encodes for the AGO-4 Argonaute protein (LOC_Os04g06770). AGO proteins, in addition to be regulatory factors of endogenous gene expression, also play a critical role in the defense against viruses through interference with small RNA of viral origin which bind to AGOs and serve as a guide for it to cut new viral RNA particles (Mallory and Vaucheret 2011)(Silva-Martins et al., 2020). This system is a common defense mechanism against pathogens, and AGO-4 might well be associated with resistance to RHBV. We are currently carrying CRISPR-Cas9 knock-out experiments in AGO-4 in order to test this hypothesis.

A distinct QTL for RHBV incidence on chromosome 4, qHBV4.2 WAS, was identified In the WAS 208 ' BBT 50 cross. This QTL was also a major one, explaining $~ 50 \%$ of the phenotypic variation. The region contains genes associated with cold tolerance (SAPK7) (Basu and Roychoudhury, 2014) and photooxidative stress (OsAPX7)(Caverzan et al. 2014), and a more interesting gene encoding for a zinc fingertype C3H protein (LOC_Os04g35800). This class of proteins has been found to be associated with resistance viruses in animals through degradation of viral RNA (Gao et al. 2002; Mao et al. 2013). Although there are no reports so far of its involvement in resistance to viruses in plants, it has been found to be associated with response to other types of pathogens (and abiotic stress) (Deng et al. 2012; Jan et al. 2013), which makes it an interesting candidate for RHBV resistance. Another candidate is a gene encoding for a MAPKKK kinase, which belongs to a signaling cascade that plays a major role in disease resistance in eukaryotes. This gene is also an interesting candidate because the activation of MAPK proteins occurs in the earliest stages after the interaction of the pathogen with the plant (Meng and Zhang 2013), which coincides well with the identification of this QTL through the assessment of incidence, but not severity, indicating that it - like qHBV4.1 - exerts its action in the early stages of the interaction of RHBV with the plant.

In contrast with the two QTLs identified on chromosome 4 that are predominantly associated with incidence, $q H B V 11.1$ has a greater effect on disease severity. This could suggest a later action, in a second stage of the interaction of the plant with the virus, after the virus manages to enter the cells and to propagate. In this scenario $q H B V 11.1$ would have a key role in diminishing the damage caused by the virus. This is thus more a "tolerance QTL". 
It has been proposed that the resistance to RHBV comes mostly from Japonica germplasm (Morales and Jennings 2010). If this was the case, and to explain that the resistance sources studied here are of Indica type, one would need to assume that the region of $q H B V 11.1$ was inherited from Japonica through introgression into Indica. This is not supported by the clustering analysis, which showed that the WAS 208 and Badka parents, for this region, are grouped together with Indica type accessions such as IR8. Therefore, this QTL does not originate from the Japonica cluster.

A search for candidate genes for qHBV11.1 evidenced a co-localization with a QTL for resistance to Rice stripe virus (RSV) found in different genetic backgrounds: in the Indica varieties Teqing ( $q S T V 11^{T Q}$ ) (Wu et al. 2011) and Shingwang ( $q S T V 11^{S G}$ ) (Kwon et al. 2012), the Aus varieties Kasalath (qSTV1 1 ${ }^{\text {KAS }}$ ) (Zhang et al. 2011), N22 (qSTV11.1) (Wang et al. 2013) and Dular (Wu et al. 2011), and in the Japonica Kanto 72 (Maeda et al. 2006). Whether those QTLs correspond to the same locus or to different, linked loci still needs to be clarified. The hypothesis of a common defense mechanism acting against RHBV and RSV seems plausible, as both are RNA viruses of the same genus, although it has been found that RHBV is more related to other tenuiviruses like Echinochloa hoja blanca virus (EHBV) and Urochloa hoja blanca virus (UHBV) than to RSV (Fauquet et al., 2005), besides not being serologically related (Morales and Jennings 2010). Further studies of fine mapping and cloning of $q S T V 11^{K A S}$ showed that the gene responsible for resistance to RSV encodes a sulfotransferase that catalyzes the conversion of salicylic acid to its sulfated form. Although it is not clear how this process confers resistance against the virus, it was found that the susceptible allele of this gene is not capable of inducing this conversion (Wang et al. 2014). Salicylic acid has been found to be essential in the initiating signal to activate systemic resistance against Tobacco mosaic virus (Zhu et al. 2014), and also plays a central role in the hypersensitive response against Potato virus Y (PVY) (Baebler et al. 2014). It has even been reported as a direct inhibitor of the replication of Tomato bush dwarf virus (TBSV) (Tian et al. 2015). It is thus plausible that the STV11 gene is involved in resistance to RHBV. We are currently analyzing knockout lines obtained by CRISPR-Cas9 in STV11 to verify this hypothesis.

A second QTL on chromosome 11, qHBV11.2, was identified for disease incidence in the two crosses involving WAS 208 and PTB 25. Based on the variation found in the clustering analysis - and assuming the QTL is the same in the two crosses - it is possible that WAS 208 and PTB 25 have different allelic variants of $q H B V 11.2$ with a different effect on disease resistance, which could explain that in PTB 25 it was also associated with severity. The region could also correspond to two distinct, linked QTLs in the two populations, since their support intervals are quite large (>3 Mpb). To answer this question, a fine mapping study of the region using larger $\mathrm{F}_{2}$ populations would be needed.

An additional QTL for RHBV incidence, $q H B V 6$, was identified In the PTB 25 ' BBT 50 cross on chromosome 6. In a previous GWAS experiment, the same region was identified in the genotypes PTB 25 and Pokkali (Cruz-Gallego et al. 2018), also supported by a biparental QTL analysis in the $F_{2: 3}$ cross FD 50 ' WC 366 (our unpublished data). A search for genes in this region found the OsBBI1 gene that participates in various biological processes, among which is the innate immune response. OsBBI1's 
expression is induced by the fungus Magnaporthe oryzae and chemical inducers such as salicylic acid (Li et al. 2011), which, as discussed above, is also associated with systemic resistance to viruses. OsBBI1 is thus a good candidate gene for $q H B V 6$.

Altogether these results show that resistance to RHBV disease is controlled by multiple quantitative genetic factors of different origins, with varying effects and action mode. The identification of strong candidate genes underlying the detected QTLs supports the idea that resistance is mediated by different defense mechanisms such as viral gene silencing and the salicylic acid pathway. This hypothesis has proven true for other study models such as in the Citrus tristeza virus (CTV) where it has been found that silencing of key genes in these defense pathways increases the spread of the virus and its accumulation in the plant(Gómez-Muñoz et al. 2017). A considerable amount of work is still needed to understand the fine mechanisms behind defense against RHBV.

\section{Resistance QTLs in the susceptible parent}

In the PTB 25 ' BBT 50 population, two QTLs for RHBV incidence were identified on chromosomes 9 and 10 , of which the allele that reduces the affected leaf area is brought by BBT 50 . One explanation could be that PTB 25 carries susceptibility alleles at these QTLs. However, this is unlikely since inactivation of a susceptibility gene by the resistant allele results in increased resistance. Genetically, the resistant allele of a susceptibility gene is therefore generally recessive. This is not what we observed, since the mean ALA of the heterozygous class AB is more similar to the susceptible class AA (PTB 25) than to the BB class (BBT 50). Therefore, the most likely explanation is that the three other resistant parents (FD 2000, WC 366 and Badka) and the susceptible parent (BBT 50) carry resistant alleles at these QTL, while the PTB 25 parent does not.

\section{Integration of QTLs into a RHBV disease resistance model}

Based on the QTLs associated with RHBV resistance, we propose a simplistic model that draws the possible processes involving these loci. The QTLs qHBV4.1 and qHBV4.2 were found to be most associated with disease incidence, so it is likely that they are involved in the first phase of virus-plant interaction. These QTL may be inhibiting the translation of viral RNA, either by direct action on them or through other genes for degradation. The effect of these QTLs on the incidence, indicates that this mechanism might be the most important for the resistance of the plant to the virus. In the scenario where the favorable alleles of qHBV4.1 or qHBV4.2 are not present or that the virus manages to overcome this barrier and to propagate in the plant, an additional mechanism involving $q H B V 11.1$ would be hampering the multiplication of the virus. This could occur by direct action, inhibiting the synthesis of new viral particles, or more likely, serving as a trigger signal for the activation of defense genes of the systemic resistance system. Although this mechanism would not provide complete resistance to the virus, it would considerably reduce the damage - meaning less leaf area affected. The qHBV6 QTL is also related to the severity of the disease, so it is possible that it also participates in this same mechanism. Although the 
role of the susceptibility QTLs $q H B V$ 9 and $q H B V 10$ is more difficult to interpret, it is likely that they are negatively regulating the activation of defense genes against the virus.

\section{Abbreviations}

ALA : affected leaf area

Badka: Badkalamkati variety, accession number IRGC 45011

BBT 50: Bluebonnet 50 variety

CIAT- Centro Internacional de Agricultura Tropical (now Alliance Bioversity-CIAT)

CIM: composite interval mapping

cM: centimorgan

CTV: Citrus tristeza virus

DAl: days after infestation

DNA: deoxyribonucleic acid

EDTA:Ethylenediaminetetraacetic acid

EHBV: Echinochloa hoja blanca virus

FD 50: Fedearroz 50 variety, accession number IRGC 1799-1-1

FD 2000: Fedearroz 2000 variety, accession number IRGC 124388

FLAR: Fondo Latinoamericano para Arroz de Riego

fsGBS: flexible and scalable genotyping by sequencing

IFC: integrated fluidic circuit

LOD: logarithm in base 10 of likelihoods odds

MATAB: mixed alkyltri-methylammonium bromide

MEG: maternally expressed gene

MLGM: generalized linear mixed model

NBS-LRR: nucleotide binding site-leucine-rich repeat 
PCR: polymerase chain reaction

PTGS: post-transcriptional gene silencing

PTB 25: PTB 25 variety, accession number IRGC 6386

PVY: Potato virus Y

QTL: quantitative trait locus

$\mathrm{RHB}$ : rice hoja blanca disease

RHBV: Rice hoja blanca virus

RNA: ribonucleic acid

RSV: Rice stripe virus

SD: segregation distortion

SIM: simple interval mapping

SMR: single-marker regression

SNP: single nucleotide polymorphism

TBSV: Tomato bush dwarf virus

TGS: transcriptional gene silencing

UHBV: Urochloa hoja blanca virus

WAS 208: WAS 208-B-B-5-1-1-3 variety, accession number IRGC 121855

\section{Declarations}

\section{Ethical Approval and Consent to participate}

Not applicable

\section{Consent for publication}

Not applicable

\section{Availability of supporting data}


The datasets used and/or analysed during the current study are available from the corresponding author on reasonable request.

\section{Competing interests}

The authors declare that they have no competing interests

\section{Funding}

The following programs partially supported this initiative: The Latin American Fund for Irrigated Rice (FLAR), the RICE CGIAR Research Program (RICE CRP), and the OMICAS program (Optimización Multiescala In-Silico de Cultivos Agrícolas Sostenibles (Infraestructura y Validación en Arroz y Caña de Azúcar), sponsored within the Colombian Scientific Ecosystem by the World Bank, The Colombian Ministry of Science, Technology and Innovation (MINCIENCIAS), ICETEX, The Colombian Ministry of Education and the Colombian Ministry of Industry and Tourism under GRANT ID: FP-44842-217-2018.

\section{Authors' contributions}

AS wrote the draft manuscript and performed the SNP design and QTL analysis, MEM set up the disease severity experiments, CQ supervised the SNP genotyping, JQ did the statistical treatment of phenotype data, JT led the Agrobiotechnology laboratory, EG led the FLAR, MC supervised the phenotyping experiments, ML designed the QTL experiments and edited the manuscript, MC and ML supervised AS work.

\section{Acknowledgements}

We warmly thank Drs. Laurence Albar, Sébastien Cunnac, Mathilde Hutin and Marlène Lachaux from the IRD for their useful comments on the manuscript.

\section{References}

1. Baebler Š, Witek K, Petek M, et al (2014) Salicylic acid is an indispensable component of the Ny-1 resistance-gene-mediated response against Potato virus $Y$ infection in potato. Journal of Experimental Botany 65:1095-1109. doi: 10.1093/jxb/ert447

2. Campbell CL, Neher DA (1994) Estimating disease severity and incidence. In: Epidemiology and Management of Root Diseases (pp. 117-147). Springer, Berlin, Heidelberg.

3. Carbonell A, Carrington JC (2015) Antiviral roles of plant ARGONAUTES. Current Opinion in Plant Biology 27:111-117. doi: 10.1016/j.pbi.2015.06.013 
4. Caverzan A, Bonifacio A, Carvalho Fel, et al (2014) The knockdown of chloroplastic ascorbate peroxidases reveals its regulatory role in the photosynthesis and protection under photo-oxidative stress in rice. Plant Science 214:74-87. doi: 10.1016/j.plantsci.2013.10.001

5. Cruz-Gallego M, Rebolledo MC, Cuasquer JB, et al (2018) Identification of new sources of resistance to RHBV - Rce hoja blanca virus. Acta Agronomica 67:368-374. doi: 10.15446/acag.v67n2.61334

6. Deng H, Liu H, Li X, et al (2012) A CCCH-type zinc finger nucleic acid-binding protein quantitatively confers resistance against rice bacterial blight disease. Plant Physiology 158:876-889. doi:

10.1104/pp.111.191379

7. Duan $\mathrm{C}-\mathrm{G}$, Zhang $\mathrm{H}$, Tang $\mathrm{K}$, et al (2015) Specific but interdependent functions for Arabidopsis AGO4 and $A G O 6$ in RNA-directed DNA methylation. EMBO Journal 34:581-592. doi:

10.15252/embj.201489453

8. Duitama J, Quintero JC, Cruz DF, et al (2014) An integrated framework for discovery and genotyping of genomic variants from high-throughput sequencing experiments. Nucleic Acids Research 42:e44. doi: 10.1093/nar/gkt1381

9. Duitama J, Silva A, Sanabria Y, et al (2015) Whole genome sequencing of elite rice cultivars as a comprehensive information resource for marker assisted selection. PLoS ONE 10:e0124617-20. doi: 10.1371/journal.pone.0124617

10. Fragoso CA, Moreno M, Wang Z, et al (2017) Genetic architecture of a rice Nested Association Mapping population. G3 | Genes, Genomes, Genetics g3.117.041608-15. doi: 10.1534/g3.117.041608

11. Gao G, Guo X, Goff SP (2002) Inhibition of retroviral RNA production by ZAP, a CCCH-type zinc finger protein. Science 297:1703-1706. doi: 10.1126/science.1074276

12. Gómez-Muñoz N, Velázquez K, Vives MC, et al (2017) The resistance of sour orange to Citrus tristeza virus is mediated by both the salicylic acid and RNA silencing defence pathways. Molecular Plant Pathology 18:1253-1266. doi: 10.1111/mpp.12488

13. Hayano-Saito, Y., Hayashi, K., 2020. Stvb-i, a Rice Gene Conferring Durable Resistance to Rice stripe virus, Protects Plant Growth From Heat Stress. Front. Plant Sci. 11, 519. https://doi.org/10.3389/fpls.2020.00519

14. Silva-Martins, G., Bolaji, A., Moffett, P., 2020. What does it take to be antiviral? An Argonaute-centered perspective on plant antiviral defense. J. Exp. Bot. 71, 6197-6210.

https://doi.org/10.1093/jxb/eraa377

15. Heffelfinger C, Fragoso CA, Lorieux M (2017) Constructing linkage maps in the genomics era with MapDisto 2.0. Bioinformatics 1-2. doi: 10.1093/bioinformatics/btx177

16. Heffelfinger C, Fragoso CA, Moreno MA, et al (2014) Flexible and scalable genotyping-by-sequencing strategies for population studies. BMC Genomics 15:979. doi: 10.1186/1471-2164-15-979

17. Jan A, Maruyama K, Todaka D, et al (2013) OsTZF1, a CCCH-tandem zinc finger protein, confers delayed senescence and stress tolerance in rice by regulating stress-related genes. Plant Physiology 161:1202-1216. doi: 10.1104/pp.112.205385 
18. Joehanes R, Nelson JC (2008) QGene 4.0, an extensible Java QTL-analysis platform. Bioinformatics 24:2788-2789. doi: 10.1093/bioinformatics/btn523

19. Kosambi DD (1944) The Estimation of Map Distances from Recombination Values. Annals of Eugenics 12:172-175.

20. Kwon T, Lee J-H, Park S-K, et al (2012) Fine mapping and identification of candidate rice genes

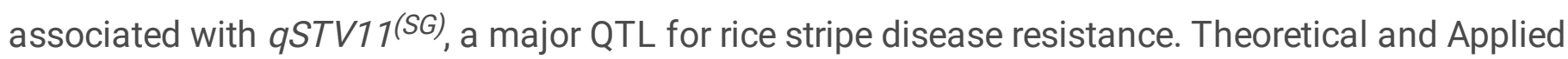
Genetics 125:1033-1046. doi: 10.1007/s00122-012-1893-8

21. Li J-Y, Wang J, Zeigler RS (2014) The 3,000 rice genomes project: new opportunities and challenges for future rice research. Gigascience 3:1-3. doi: 10.1186/2047-217X-3-8

22. Li W, Zhong S, Li G, et al (2011) Rice RING protein OsBBI1 with E3 ligase activity confers broadspectrum resistance against Magnaporthe oryzae by modifying the cell wall defence. Cell Research 21:835-848. doi: 10.1038/cr.2011.4

23. Lorieux M (2012) MapDisto: fast and efficient computation of genetic linkage maps. Molecular Breeding 30:1231-1235. doi: 10.1007/s11032-012-9706-y

24. Lorieux M (2018) Is this a fake QTL? A short note on analysis of multiple QTL peaks on the same chromosome. BioRXiv 1-7. doi: 10.1101/270736

25. Maeda H, Matsushita K, lida S, Sunohara Y (2006) Characterization of two QTLs controlling resistance to Rice stripe virus detected in a Japanese upland rice line, Kanto 72. Breeding Science 56:359-364. doi: 10.1270/jsbbs.56.359

26. Mallory A, Vaucheret $H$ (2011) Form, function, and regulation of ARGONAUTE proteins. The Plant Cell Online 22:3879-3889. doi: 10.1105/tpc.110.080671

27. Mao R, Nie H, Cai D, et al (2013) Inhibition of hepatitis B virus replication by the host zinc finger antiviral protein. PLoS Pathogens 9:e1003494. doi: 10.1371/journal.ppat.1003494

28. McHale L, Tan X, Koehl P, Michelmore RW (2006) Plant NBS-LRR proteins: adaptable guards. Genome Biology 7:212-11. doi: 10.1186/gb-2006-7-4-212

29. Meng X, Zhang S (2013) MAPK cascades in plant disease resistance signaling. Annual Review of Phytopathology 51:245-266. doi: 10.1146/annurev-phyto-082712-102314

30. Morales F and Jennings P (2010) Rice hoja blanca: a complex plant-virus-vector pathosystem. CAB Reviews. doi: 10.1079/PAVSNNR20105043

31. Prins P, Jansen RC, Broman KW (2010) R/qtl: high-throughput multiple QTL mapping. Bioinformatics 26:2990-2992. doi: 10.1093/bioinformatics/btq565

32. Risterucci AM, Grivet L, N'Goran J, et al (2000) A high-density linkage map of Theobroma cacao L. Theoretical and Applied Genetics 101:948-955

33. Romero LE, Lozano I, Garavito A, et al (2014) Major QTLs control resistance to Rice hoja blanca virus and its vector Tagosodes orizicolus. G3। Genes, Genomes, Genetics 4:133-142. doi: $10.1534 / g 3.113 .009373$ 
34. Tian M, Sasvari Z, Gonzalez PA, et al (2015) Salicylic acid inhibits the replication of Tomato bushy stunt virus by directly targeting a host component in the replication complex. Molecular PlantMicrobe Interactions 28:379-386. doi: 10.1094/MPMI-09-14-0259-R

35. Wang Q, Liu Y, He J, et al (2014) STV11 encodes a sulphotransferase and confers durable resistance to Rice stripe virus. Nature Communications 5:4768. doi: $10.1038 / \mathrm{ncomms} 5768$

36. Wang Q, Liu Y, Hu J, et al (2013) Detection of quantitative trait loci (QTLs) for resistances to small brown planthopper and Rice Stripe Virus in rice using recombinant inbred lines. International journal of molecular sciences 14:8406-8421. doi: 10.3390/ijms14048406

37. Wang $S$, Tan $Y$, Tan $X$, et al (2009) Segregation distortion detected in six rice $F_{2}$ populations generated from reciprocal hybrids at three altitudes. Genetics Research 91:345-353. doi: $10.1017 /$ S0016672309990176

38. Wu X, Zuo S, Chen Z, et al (2011) Fine mapping of $q S T V 11^{T Q}$, a major gene conferring resistance to rice stripe disease. Theoretical and Applied Genetics 122:915-923. doi: 10.1007/s00122-010-1498-Z

39. Yamamoto E, Yonemaru J-I, Yamamoto T, Yano M (2012) OGRO: The overview of functionally characterized genes in rice online database. Rice 5:1-10. doi: 10.1186/1939-8433-5-26

40. Zhang Y-X, Wang Q, Jiang L, et al (2011) Fine mapping of qSTV11 KAS, a major QTL for rice stripe disease resistance. Theoretical and Applied Genetics 1-14. doi: 10.1007/s00122-011-1557-0

41. Zhu F, Xi D-H, Yuan S, et al (2014) Salicylic acid and jasmonic acid are essential for systemic resistance against Tobacco mosaic virus in Nicotiana benthamiana. Molecular Plant-Microbe Interactions 27:567-577. doi: 10.1094/MPMI-11-13-0349-R

\section{Tables}

Table 1 Summary of genetic maps characteristics in the four populations. Map sizes are expressed in cM calculated with Kosambi function

\begin{tabular}{llllll}
\hline Cross & $\begin{array}{l}\text { Population } \\
\text { size }\end{array}$ & Nb SNPS & Nb SSRs & $\begin{array}{l}\text { Total } \\
\text { markers }\end{array}$ & $\begin{array}{l}\text { Map size } \\
\text { (cM) }\end{array}$ \\
\hline WAS 208 $\times$ BBT 50 & 104 & 207 & 2 & 209 & 1,296 \\
Badka $\times$ BBT 50 & 105 & 226 & 1 & 227 & 1,570 \\
PTB 25 $\times$ BBT 50 & 108 & 184 & 1 & 185 & 1,617 \\
FD 2000 $\times$ BBT 50 & 105 & 217 & 0 & 217 & 1,630 \\
\hline
\end{tabular}


Table 2 Trait correlation values in each population, and in the four populations combined

A. WAS $208 \times$ BBT50

\begin{tabular}{lrrrrrr}
\hline & INCIDENCE & INCID_MO_V1 & INCID_MO & SEVERITY & SEVER_MO_V1 & SEVER_MO \\
\hline INCIDENCE & 1 & 1 & 1 & 0.42 & 0.42 & 0.42 \\
INCIDENCE_MO_V1 & 1 & 1 & 1 & 0.42 & 0.42 & 0.42 \\
INCIDENCE_MO & 1 & 1 & 1 & 0.42 & 0.42 & 0.42 \\
SEVERITY(ALA) & 0.42 & 0.42 & 0.42 & 1 & 1 & 1 \\
SEVERITY_MO_V1 & 0.42 & 0.42 & 0.42 & 1 & 1 & 1 \\
SEVERITY_MO & 0.42 & 0.42 & 0.42 & 1 & 1 & 1 \\
\hline
\end{tabular}

\section{B. Badka $\times$ BBT50}

\begin{tabular}{lrrrrrr}
\hline & INCIDENCE & INCID_MO_V1 & INCID_MO & SEVERITY & SEVER_MO_V1 & SEVER_M0 \\
\hline INCIDENCE & 1 & 1 & 1 & 0.625 & 0.625 & 0.625 \\
INCIDENCE_MO_V1 & 1 & 1 & 1 & 0.625 & 0.625 & 0.625 \\
INCIDENCE_MO & 1 & 1 & 1 & 0.625 & 0.625 & 0.625 \\
SEVERITY (ALA) & 0.625 & 0.625 & 0.625 & 1 & 1 & 1 \\
SEVERITY_MO_V1 & 0.625 & 0.625 & 0.625 & 1 & 1 & 1 \\
SEVERITY_MO & 0.625 & 0.625 & 0.625 & 1 & 1 & 1 \\
\hline
\end{tabular}

\section{PTB $25 \times$ BBT50}

\begin{tabular}{lrrrrrr}
\hline & INCIDENCE & INCID_MO_V1 & INCID_MO & SEVERITY & SEVER_MO_V1 & SEVER_MO \\
\hline INCIDENCE & 1 & 1 & 1 & 0.458 & 0.458 & 0.458 \\
INCIDENCE_MO_V1 & 1 & 1 & 1 & 0.458 & 0.458 & 0.458 \\
INCIDENCE_MO & 1 & 1 & 1 & 0.458 & 0.458 & 0.458 \\
SEVERITY (ALA) & 0.458 & 0.458 & 0.458 & 1 & 1 & 1 \\
SEVERITY_MO_V1 & 0.458 & 0.458 & 0.458 & 1 & 1 & 1 \\
SEVERITY_MO & 0.458 & 0.458 & 0.458 & 1 & 1 & 1 \\
\hline
\end{tabular}

\section{FD $2000 \times$ BBT50}

\begin{tabular}{lrrrrrr}
\hline & INCIDENCE & INCID_MO_V1 & INCID_MO & SEVERITY & SEVER_MO_V1 & SEVER_MO \\
\hline INCIDENCE & 1 & 1 & 1 & 0.655 & 0.655 & 0.655 \\
INCIDENCE_MO_V1 & 1 & 1 & 1 & 0.655 & 0.655 & 0.655 \\
INCIDENCE_MO & 1 & 1 & 1 & 0.655 & 0.655 & 0.655 \\
SEVERITY (ALA) & $\mathbf{0 . 6 5 5}$ & 0.655 & 0.655 & 1 & 1 & 1 \\
SEVERITY_MO_V1 & 0.655 & 0.655 & 0.655 & 1 & 1 & 1 \\
SEVERITY_MO & 0.655 & 0.655 & 0.655 & 1 & 1 & 1 \\
\hline
\end{tabular}

E. Four crosses combined

\begin{tabular}{lrrrrrr}
\hline & INCIDENCE & INCID_MO_V1 & INCID_MO & SEVERTTY & SEVER_MO_V1 & SEVER_MO \\
\hline INCIDENCE & 1 & 0.891 & 0.898 & 0.613 & 0.481 & 0.484 \\
INCIDENCE_MO_V1 & 0.891 & 1 & 0.993 & 0.449 & 0.538 & 0.538 \\
INCIDENCE_MO & 0.898 & 0.993 & 1 & 0.448 & 0.534 & 0.537 \\
SEVERITY (ALA) & 0.613 & 0.449 & 0.448 & 1 & 0.829 & 0.835 \\
SEVERITY_MO_V1 & 0.481 & 0.538 & 0.534 & 0.829 & 1 & 0.993 \\
SEVERITY_MO & 0.484 & 0.538 & 0.537 & 0.835 & 0.993 & 1 \\
\hline
\end{tabular}


Table 3 Summary statistics for QTL detected with Simple Interval Mapping (SIM) analysis in the four crosses, and joint analysis, with Qgene version 4.40. Positions in Mbp on Nipponbare genome (MSU v7). Empirical threshold $\alpha_{0.01}$ calculated with 10,000 permutations

\begin{tabular}{|c|c|c|c|c|c|c|c|c|c|c|c|c|c|c|}
\hline Trait & $\begin{array}{c}\text { QTL } \\
\text { name }\end{array}$ & $\begin{array}{r}\text { WAS } \\
208 \\
\end{array}$ & $\begin{array}{c}\text { Bad- } \\
\text { ka }\end{array}$ & $\begin{array}{c}P T B \\
25 \\
\end{array}$ & $\begin{array}{c}F D \\
2000 \\
\end{array}$ & $\begin{array}{c}\text { Joint } \\
(4 \\
\text { pop.) }\end{array}$ & $\begin{array}{c}\text { Chro } \\
\text { mo- } \\
\text { some }\end{array}$ & $\begin{array}{c}\text { Peak } \\
\text { (Mbp) }\end{array}$ & $R^{2}$ & $\begin{array}{c}\text { Additivity } \\
\text { (A) }\end{array}$ & $\begin{array}{c}\text { Dominance } \\
\text { (D) }\end{array}$ & $|D / A|$ & $\begin{array}{c}\text { LOD } \\
\text { score }\end{array}$ & $\begin{array}{r}\text { Permut. } \\
\text { threshold } \\
\alpha=0.01\end{array}$ \\
\hline \multirow[t]{4}{*}{ Incidence } & $q H B V 4.1$ & & $\checkmark$ & & & & 4 & $3.56-6.47$ & 0.63 & -24.14 & -1.17 & 0.05 & 20.97 & 4.43 \\
\hline & & & & $\checkmark$ & & & & $0.22-4.19$ & 0.60 & -24.47 & -5.24 & 0.21 & 21.26 & 4.55 \\
\hline & & & & & $\checkmark$ & & & $3.56-3.57$ & 0.34 & -14.69 & -0.46 & 0.03 & 9.11 & 4.40 \\
\hline & & & & & & $\checkmark$ & & $3.56-3.57$ & 0.42 & -17.51 & -2.51 & 0.14 & 47.00 & 4.50 \\
\hline Incidence & $q H B V 4.2^{\text {Whszas }}$ & $\checkmark$ & & & & & 4 & 21.8 & 0.52 & -18.44 & 4.90 & 0.27 & 15.49 & 4.47 \\
\hline Incidence & qHBV6. $1^{\text {PTB2S }}$ & & & $\checkmark$ & & & 6 & $1.87-3.08$ & 0.15 & -16.79 & -3.69 & 0.22 & 3.64 & 4.55 \\
\hline \multirow[t]{2}{*}{ Incidence } & $q H B V 11.1$ & & & & $\checkmark$ & & 11 & $18.78-18.87$ & 0.29 & -14.25 & -3.50 & 0.25 & 7.43 & 4.40 \\
\hline & & & & & & $\checkmark$ & & 18.5 & 0.11 & -9.33 & -4.11 & 0.44 & 10.40 & 4.37 \\
\hline \multirow[t]{2}{*}{ Incidence } & qHBV11.2 & $\checkmark$ & & & & & 11 & $7.43-17.23$ & 0.09 & -8.51 & 1.98 & 0.23 & 2.08 & 4.47 \\
\hline & & & & $\checkmark$ & & & & $7.43-8.60$ & 0.09 & -9.58 & -6.68 & 0.70 & 2.16 & 4.55 \\
\hline \multirow[t]{4}{*}{ ALA } & $q H B V 4.1$ & & $\checkmark$ & & & & 4 & $3.56-6.47$ & 0.31 & -13.90 & 0.43 & 0.03 & 8.31 & 4.49 \\
\hline & & & & $\checkmark$ & & & & $0.22-4.19$ & 0.30 & -10.86 & -5.41 & 0.50 & 8.50 & 4.29 \\
\hline & & & & & $\checkmark$ & & & $3.71-4.19$ & 0.25 & -9.16 & -3.73 & 0.41 & 6.69 & 4.40 \\
\hline & & & & & & $\checkmark$ & & $3.71-4.19$ & 0.23 & -9.46 & -3.95 & 0.42 & 23.40 & 4.30 \\
\hline \multirow[t]{4}{*}{ ALA } & $q H B V 11.1$ & $\checkmark$ & & & & & 11 & 18.06 & 0.21 & -8.82 & -3.17 & 0.36 & 5.32 & 4.56 \\
\hline & & & $\checkmark$ & & & & & $17.62-17.83$ & 0.19 & -10.70 & -2.33 & 0.22 & 4.68 & 4.49 \\
\hline & & & & & $\checkmark$ & & & 18.06 & 0.33 & -9.36 & -7.18 & 0.77 & 8.98 & 4.69 \\
\hline & & & & & & $\checkmark$ & & 18.06 & 0.17 & -8.65 & -3.62 & 0.42 & 17.29 & 4.37 \\
\hline
\end{tabular}


Table 4 Summary statistics for QTL detected with Composite Interval Mapping (CIM) analysis in the four crosses, and joint analysis, with Qgene version 4.40. Cofactor selection method: Forward selection, automatic, QTL cofactors instead of markers = no. Positions in Mbp on Nipponbare genome (MSU v7). Empirical threshold $\alpha_{0.01}$ calculated with 10,000 permutations

\begin{tabular}{|c|c|c|c|c|c|c|c|c|c|c|c|c|c|c|}
\hline Trait & $\begin{array}{c}\text { QTL } \\
\text { name }\end{array}$ & $\begin{array}{r}\text { WAS } \\
208 \\
\end{array}$ & $\begin{array}{c}\text { Bad- } \\
\text { ka }\end{array}$ & $\begin{array}{c}P T B \\
25 \\
\end{array}$ & $\begin{array}{c}F D \\
2000 \\
\end{array}$ & $\begin{array}{c}\text { Joint } \\
(4 \\
\text { pop.) }\end{array}$ & $\begin{array}{c}\text { Chro } \\
\text { mo- } \\
\text { some }\end{array}$ & $\begin{array}{c}\text { Peak } \\
\text { (Mbp) }\end{array}$ & $R^{2}$ & $\begin{array}{l}\text { Additivity } \\
\text { (A) }\end{array}$ & $\begin{array}{c}\text { Dominance } \\
\text { (D) }\end{array}$ & $|D / A|$ & $\begin{array}{l}\text { LOD } \\
\text { score }\end{array}$ & $\begin{array}{c}\text { Permut. } \\
\text { threshold } \\
\alpha=0.01\end{array}$ \\
\hline \multirow[t]{4}{*}{ Incidence } & qHBV 4.1 & & $\checkmark$ & & & & 4 & $3.56-4.46$ & 0.6 & -22.37 & -0.67 & 0.03 & 23.46 & 5.57 \\
\hline & & & & $\checkmark$ & & & & $3.5-4.19$ & 0.73 & -25.38 & -6.84 & 0.27 & 30.45 & 5.10 \\
\hline & & & & & $\checkmark$ & & & $3.5-3.7$ & 0.501 & -14.95 & 1.34 & 0.09 & 17.27 & 4.95 \\
\hline & & & & & & $\checkmark$ & & $3.5-3.7$ & 0.42 & -16.78 & -1.09 & 0.06 & 47.82 & 4.85 \\
\hline Incidence & $q H B V 4.2^{\text {Whacas }}$ & $\checkmark$ & & & & & 4 & $21.29-21.81$ & 0.57 & -18.75 & 3.15 & 0.17 & 18.31 & 5.47 \\
\hline Incidence & qHBV6.1 $1^{\text {PTB2S }}$ & & & $\checkmark$ & & & 6 & $0.18-1.76$ & 0.25 & -10.52 & 0.16 & 0.02 & 9.71 & 5.11 \\
\hline \multirow[t]{2}{*}{ Incidence } & $q H B V 11.1$ & & & & $\checkmark$ & & 11 & $17.8-18.52$ & 0.44 & -13.83 & -5.4 & 0.39 & 14.08 & 5.29 \\
\hline & & & & & & $\checkmark$ & & $17.8-18.52$ & 0.08 & -7.154 & -3.314 & 0.46 & 7.26 & 4.32 \\
\hline \multirow[t]{2}{*}{ Incidence } & $q H B V 11.2$ & $\checkmark$ & & & & & 11 & $7.43-17.23$ & 0.21 & -8.16 & 2.66 & 0.33 & 5.02 & 4.11 \\
\hline & & & & $\checkmark$ & & & & 7.43-16.6 & 0.242 & -10.21 & 2.45 & 0.24 & 5.90 & 4.97 \\
\hline \multirow[t]{4}{*}{ ALA } & $q H B V 4.1$ & & $\checkmark$ & & & & 4 & $3.56-4.46$ & 0.26 & -10.65 & -2.86 & 0.27 & 8.98 & 5.26 \\
\hline & & & & $\checkmark$ & & & & $3.56-4.19$ & 0.26 & -9.53 & -1.07 & 0.11 & 9.81 & 5.43 \\
\hline & & & & & $\checkmark$ & & & $3.56-4.46$ & 0.29 & -7.87 & -2.48 & 0.32 & 9.93 & 5.32 \\
\hline & & & & & & $\checkmark$ & & $3.56-4.46$ & 0.222 & -8.958 & -2.899 & 0.32 & 23.00 & 5.33 \\
\hline \multirow[t]{4}{*}{ ALA } & $q H B V 11.1$ & $\checkmark$ & & & & & 11 & $18.0-18.8$ & 0.19 & -8.71 & -2.94 & 0.34 & 5.32 & 4.84 \\
\hline & & & $\checkmark$ & & & & & $17.8-18.5$ & 0.23 & -10.27 & -3.19 & 0.31 & 6.09 & 4.95 \\
\hline & & & & & $\checkmark$ & & & $17.8-18.5$ & 0.37 & -8.74 & -7.01 & 0.80 & 11.52 & 5.47 \\
\hline & & & & & & $\checkmark$ & & 18.06 & 0.19 & -8.03 & -2.92 & 0.36 & 18.84 & 4.62 \\
\hline
\end{tabular}


Table 5 Summary statistics for QTL detected with Simple Marker Regression (SRM) analysis in the four crosses, joint- and meta-analyses, with MapDisto version 2.0. Positions in Mbp on Nipponbare genome (MSU v7). Empirical threshold $\alpha_{0.01}$ calculated with Qgene 4.40, with 10,000 permutations

\begin{tabular}{|c|c|c|c|c|c|c|c|c|c|c|c|c|c|c|c|c|}
\hline Trait & $\begin{array}{c}Q T L \\
\text { name }\end{array}$ & $\begin{array}{r}\text { WAS } \\
208\end{array}$ & $\begin{array}{c}\text { Bad- } \\
\text { ka }\end{array}$ & $\begin{array}{c}P T B \\
25\end{array}$ & $\begin{array}{c}F D \\
2000\end{array}$ & $\begin{array}{c}\text { Joint } \\
(4 \\
\text { pop.) }\end{array}$ & $\begin{array}{c}\text { Meta } \\
(4 \\
\text { pop.) }\end{array}$ & $\begin{array}{l}\text { Chro } \\
\text { mo- } \\
\text { some }\end{array}$ & $\begin{array}{l}\text { Peak } \\
(M b p)\end{array}$ & $R^{2}$ & $\begin{array}{l}\text { Additivity } \\
\text { (A) }\end{array}$ & $\begin{array}{c}\text { Dominance } \\
\text { (D) }\end{array}$ & $|D / A|$ & F-test & $\begin{array}{c}-\log _{\text {so }} \\
\text { (p-value of } \\
\text { test) }\end{array}$ & $\begin{array}{c}\text { Permut. } \\
\text { threshold } \\
\alpha=0.01\end{array}$ \\
\hline \multirow[t]{5}{*}{ Incidence } & $q H B V 4.1$ & & $\checkmark$ & & & & & 4 & $3.56-6.47$ & 0.61 & 22.43 & -1.65 & 0.07 & 74.18 & 19.33 & 4.35 \\
\hline & & & & $\checkmark$ & & & & & $0.22-4.19$ & 0.60 & 24.47 & -5.24 & 0.21 & 77.85 & 20.67 & 4.18 \\
\hline & & & & & $\checkmark$ & & & & $3.56-3.57$ & 0.34 & 14.69 & -0.46 & 0.03 & 25.29 & 8.84 & 4.20 \\
\hline & & & & & & $\checkmark$ & & & $3.56-3.57$ & 0.42 & 17.51 & -2.51 & 0.14 & 142.30 & 46.65 & 4.29 \\
\hline & & & & & & & $\checkmark$ & & $3.56-3.57$ & - & - & - & - & - & 47.00 & * \\
\hline Incidence & qHBV4.2 waseos & $\checkmark$ & & & & & & 4 & 21.8 & 0.50 & 17.67 & 4.40 & 0.25 & 48.04 & 14.42 & 4.28 \\
\hline Incidence & qHBV $61^{\text {Pros }}$ & & & $\checkmark$ & & & & 6 & $2.97-3.08$ & 0.13 & 15.04 & -6.76 & 0.45 & 7.82 & 3.16 & 4.31 \\
\hline \multirow[t]{3}{*}{ Incidence } & $q H B V 11.1$ & & & & $\checkmark$ & & & 11 & $18.78-18.87$ & 0.29 & 14.09 & -2.92 & 0.21 & 19.45 & 7.10 & 4.22 \\
\hline & & & & & & $\checkmark$ & & & $18.52-18.87$ & 0.11 & 9.33 & -4.11 & 0.44 & 25.24 & 10.32 & 4.29 \\
\hline & & & & & & & $\checkmark$ & & $18.52-18.87$ & . & $\dot{ }$ & . & - & - & 8.91 & * \\
\hline \multirow[t]{2}{*}{ Incidence } & $q H B V 11.2$ & $\checkmark$ & & & & & & 11 & $7.43-17.23$ & 0.10 & 7.55 & 2.05 & 0.27 & 5.12 & 2.11 & 4.29 \\
\hline & & & & $\checkmark$ & & & & & $7.43-8.60$ & 0.09 & 9.15 & -6.09 & 0.67 & 5.03 & 2.08 & 4.25 \\
\hline \multirow[t]{5}{*}{ ALA } & $q H B V 4.1$ & & $\checkmark$ & & & & & 4 & $3.56-6.47$ & 0.29 & 12.85 & -1.09 & 0.09 & 21.12 & 7.67 & 4.23 \\
\hline & & & & $\checkmark$ & & & & & $0.22-4.19$ & 0.30 & 10.54 & -2.48 & 0.24 & 22.09 & 8.01 & 4.18 \\
\hline & & & & & $\checkmark$ & & & & $3.71-4.19$ & 0.25 & 8.86 & -3.19 & 0.36 & 17.23 & 6.45 & 4.38 \\
\hline & & & & & & $\checkmark$ & & & $3.56-3.71$ & 0.23 & 9.46 & -3.95 & 0.42 & 60.94 & 23.23 & 4.22 \\
\hline & & & & & & & $\checkmark$ & & $3.70-4.19$ & - & - & - & - & - & 20.75 & * \\
\hline \multirow[t]{5}{*}{ ALA } & qHBV11.1 & $\checkmark$ & & & & & & 11 & 18.06 & 0.21 & 8.82 & -3.17 & 0.36 & 13.43 & 5.17 & 4.31 \\
\hline & & & $\checkmark$ & & & & & & $17.62-17.83$ & 0.19 & 10.70 & -2.33 & 0.22 & 11.62 & 4.55 & 4.16 \\
\hline & & & & & $\checkmark$ & & & & 18.06 & 0.32 & 9.22 & -6.66 & 0.72 & 23.72 & 8.46 & 4.38 \\
\hline & & & & & & $\checkmark$ & & & 18.06 & 0.17 & 8.65 & -3.62 & 0.42 & 43.49 & 17.16 & 4.30 \\
\hline & & & & & & & $\checkmark$ & & 18.06 & - & . & - & - & - & 15.40 & • \\
\hline
\end{tabular}

Table 6 Summary of QTLs found in each resistance donor

\begin{tabular}{ccccccc}
\hline & \multicolumn{8}{c}{ Resistance donor } \\
QTL & & Chromo- & WAS & Bad- & PTB & FD \\
name & Trait & some & 208 & ka & 25 & 2000 \\
\hline$q H B V 4.1$ & Incidence & 4 & & $\checkmark$ & $\checkmark$ & $\checkmark$ \\
& ALA & 4 & & $\checkmark$ & $\checkmark$ & $\checkmark$ \\
$q H B V 4.2^{\text {WAS208 }}$ & Incidence & 4 & $\checkmark$ & & & \\
$q H B V 6.1^{\text {PTB25 }}$ & Incidence & 6 & & & $\checkmark$ & \\
$q H B V 11.2$ & Incidence & 11 & $\checkmark$ & & $\checkmark$ & \\
$q H B V 11.1$ & ALA & 11 & $\checkmark$ & $\checkmark$ & & $\checkmark$ \\
& Incidence & 11 & & & & $\checkmark$ \\
\hline
\end{tabular}




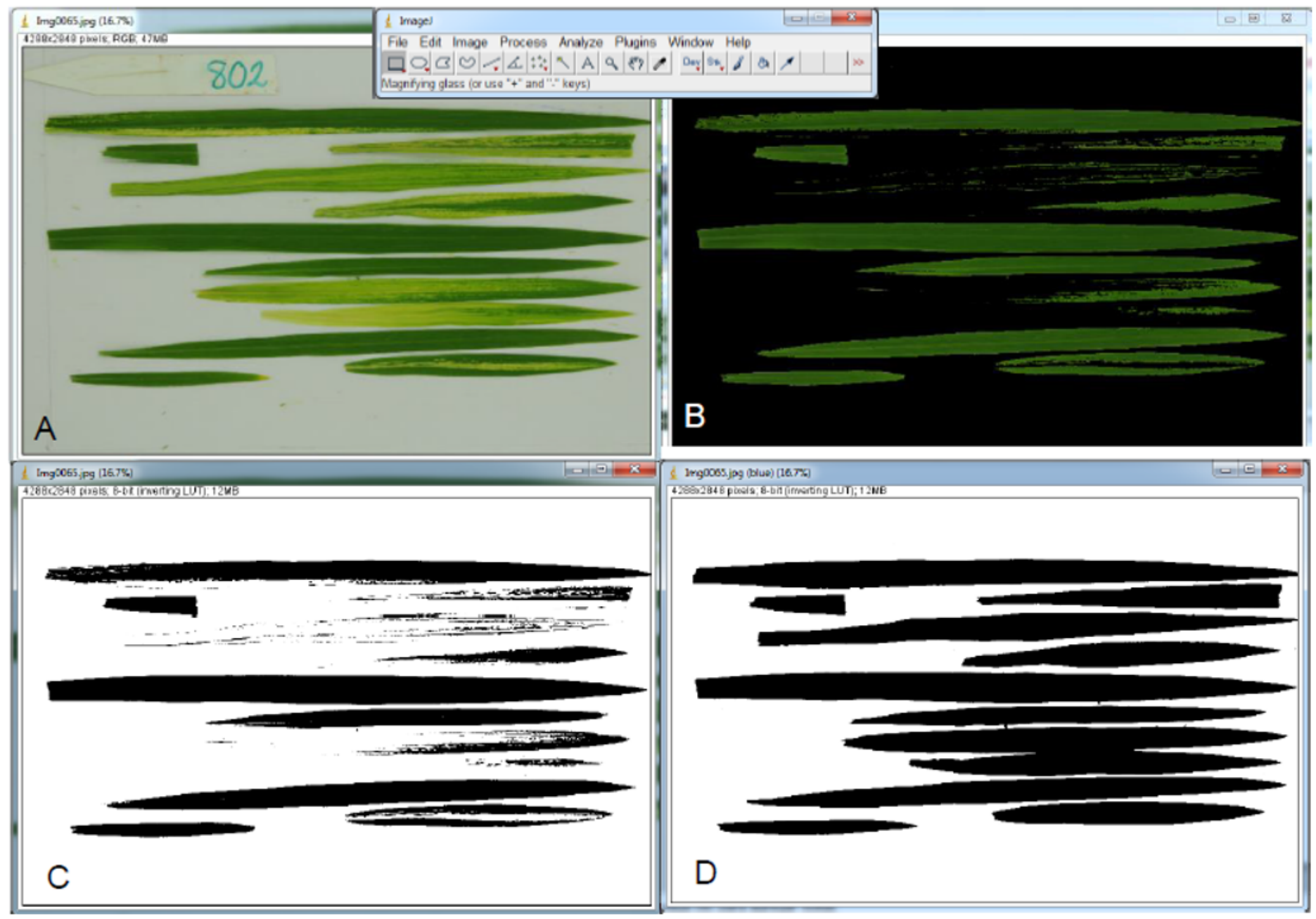

\section{Figure 1}

RHBV disease severity (\% of affected leaf area, ALA) measurement workflow. A: Image acquisition of rice leaves affected by RHBV. B: Image segmentation to separate healthy from affected leaf areas. C: Healthy leaf area binarization. D: Total leaf area binarization 
WAS $208 \times$ BBT50 - Incidence
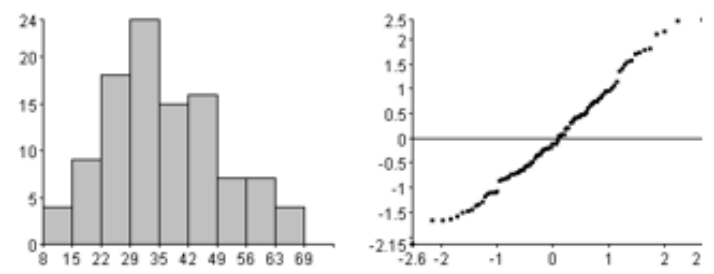

Badka $\times$ BBT50 - Incidence
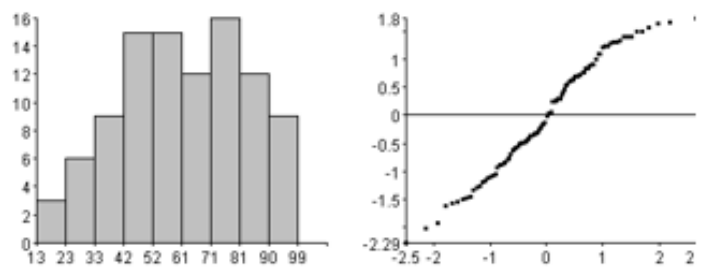

PTB $25 \times$ BBT50 - Incidence
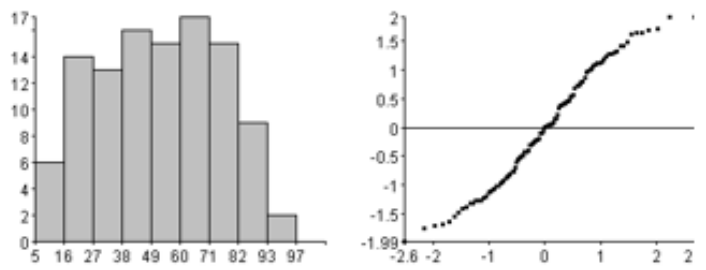

FD $2000 \times$ BBT50 - Incidence
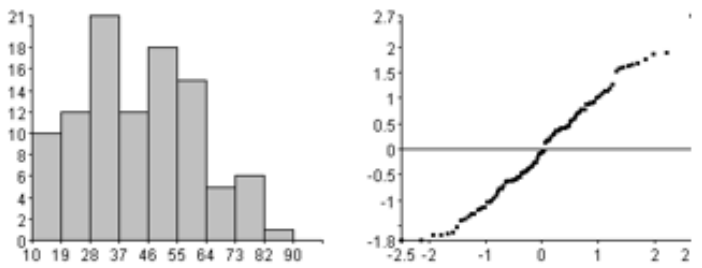

Four crosses combined - Incidence
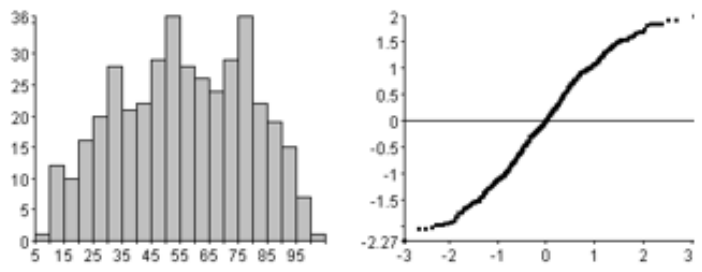

WAS $208 \times$ BBT50 - ALA
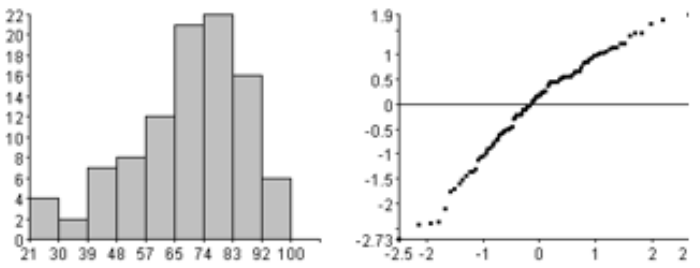

Badka $\times$ BBT50 - ALA
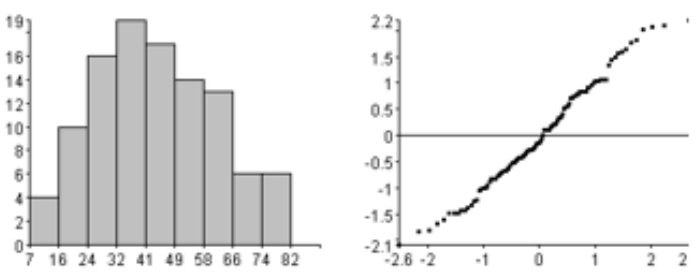

PTB $25 \times$ BBT50 - ALA
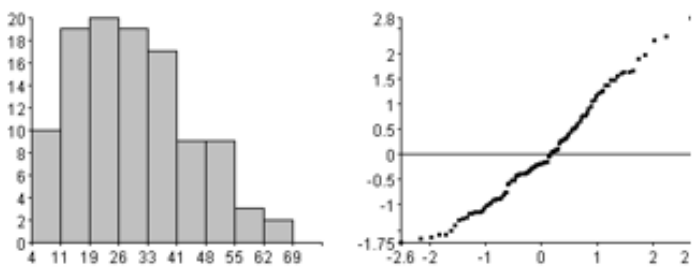

FD $2000 \times$ BBT50 - ALA
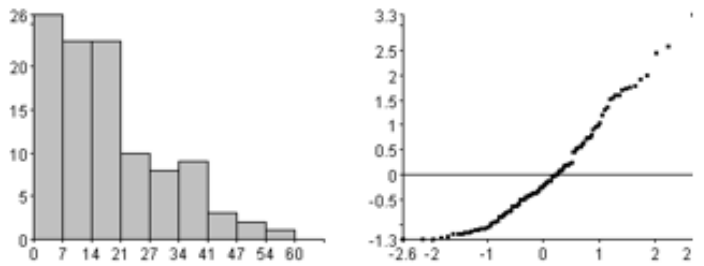

Four crosses combined - ALA
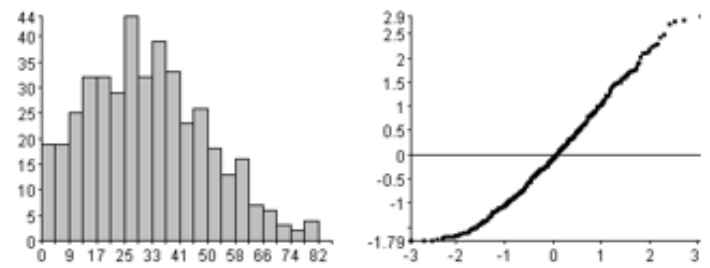

Figure 2

Distribution of the means of RHBV incidence (\% of plants with symptoms) and severity (\% of affected leaf area, ALA) in F3 families, in four indica' japonica rice mapping populations. Means in F3 families were calculated from 60 plants (incidence) or 10 plants (ALA) 
A. WAS $208 \times$ BBT50

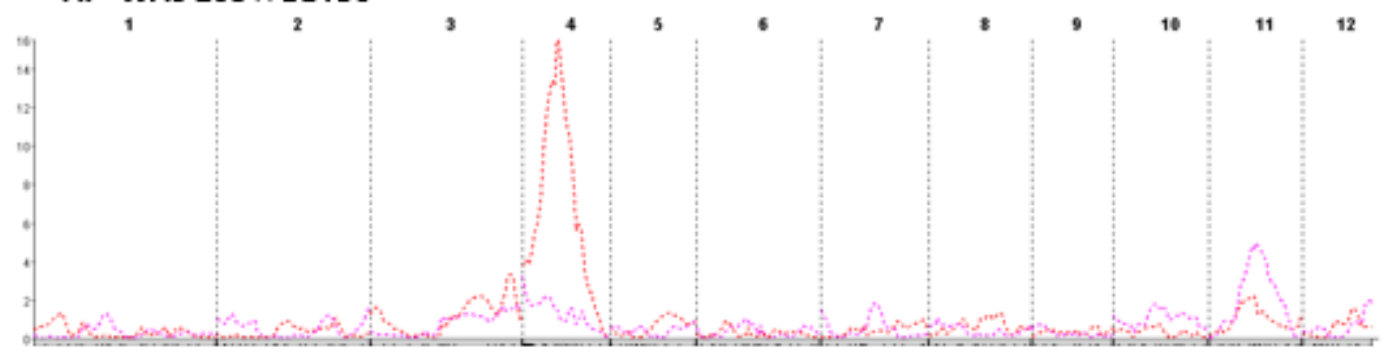

B. Badka $\times$ BBT50

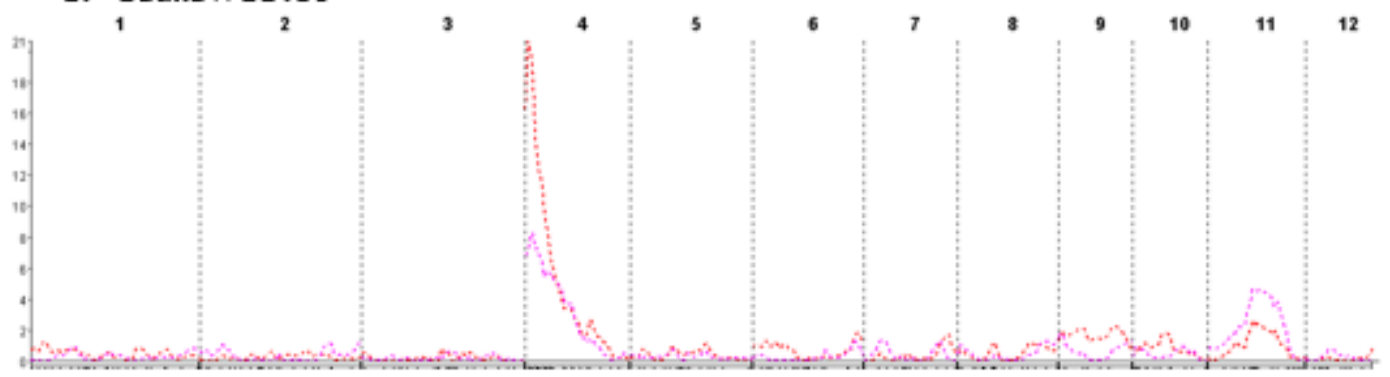

C. PTB $25 \times$ BBT50

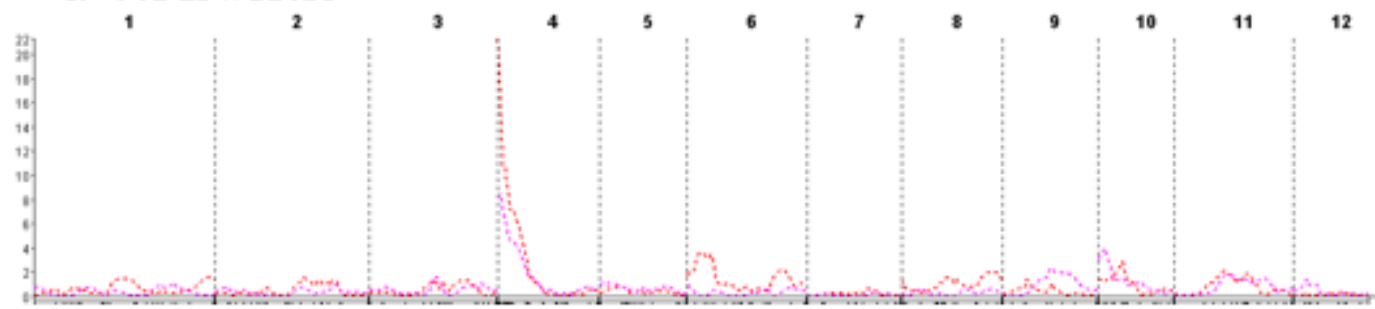

D. FD $2000 \times$ BBT50

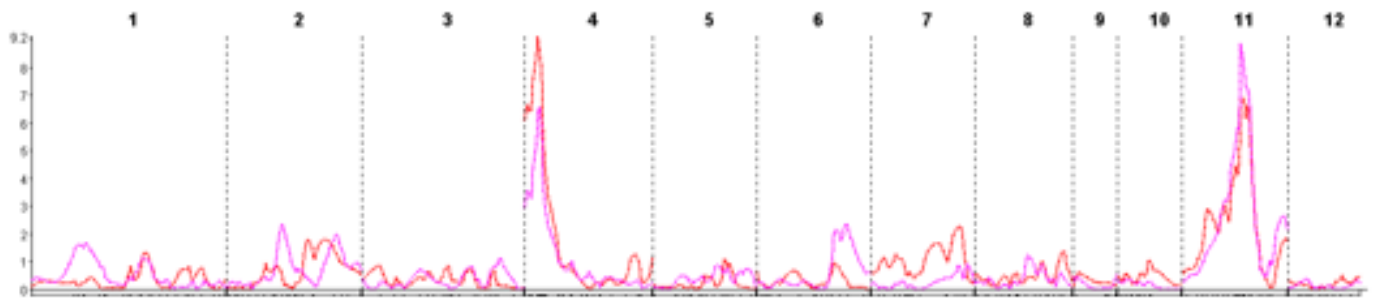

E. Four crosses combined - joint analysis

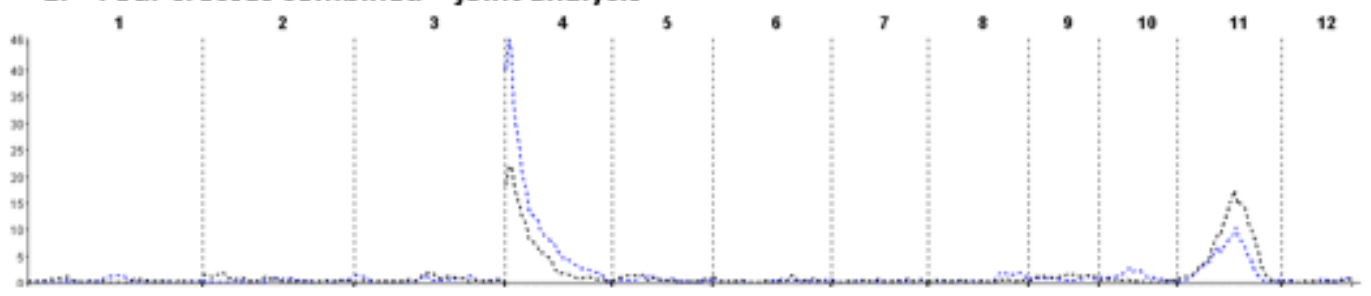

Figure 3

Whole-genome QTL plots (SIM) in the four crosses analyzed independently (A-D), and jointly (E). Red:incidence; purple: severity (ALA) 


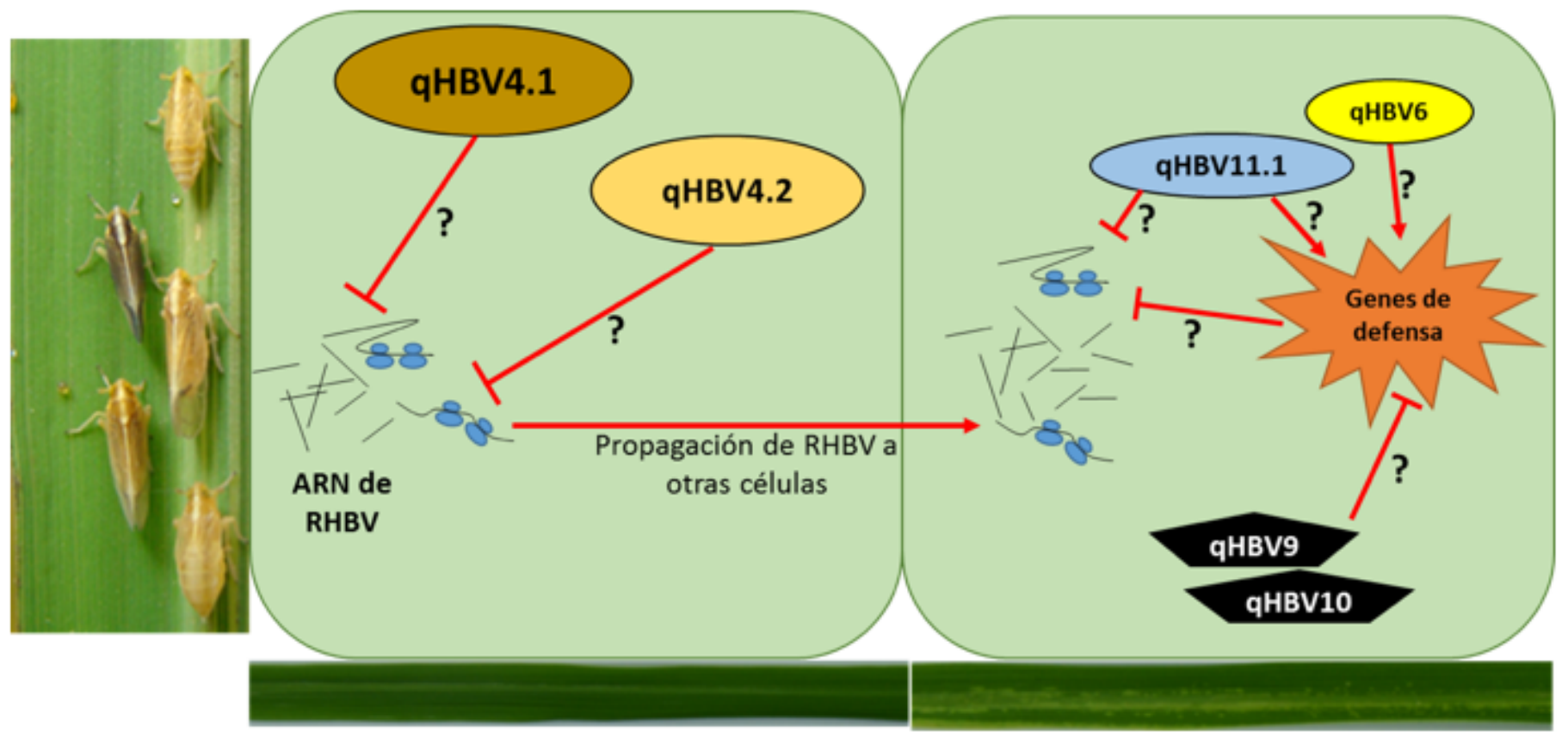

Figure 4

Hypothetical model of plant resistance mechanisms to RHBV

\section{Supplementary Files}

This is a list of supplementary files associated with this preprint. Click to download.

- Supplementalfigures.docx 